\title{
Genome-wide analysis of DNA repeats in Burkholderia cenocepacia J2315 identifies a novel adhesin-like gene unique to epidemic-associated strains of the ET-12 lineage
}

Correspondence

Arsenio M. Fialho afialho@ist.utl.pt

Received 10 July 2009

Revised 10 December 2009

Accepted 14 December 2009
Dalila Mil-Homens, ${ }^{1}$ Eduardo P. C. Rocha ${ }^{2,3}$ and Arsenio M. Fialho ${ }^{1}$

\author{
${ }^{1}$ IBB-Institute for Biotechnology and Bioengineering, Center for Biological and Chemical \\ Engineering, Instituto Superior Técnico, Lisbon 1049-001, Portugal \\ ${ }^{2}$ Atelier de Bioinformatique, Université Pierre et Marie Curie-Paris 6, Paris, F-75005 France \\ ${ }^{3}$ Microbial Evolutionary Genomics Group, CNRS URA2171, Institute Pasteur, F-75015 Paris, France
}

\section{INTRODUCTION}

The Burkholderia cepacia complex (Bcc) represents a group of bacteria commonly found in soil and aquatic habitats. Over the last 20 years, members of the Bcc have emerged as problematic opportunistic human pathogens in immunocompromised individuals and in patients with cystic fibrosis (CF) (Mahenthiralingam et al., 2005). They have the capacity of spreading between patients and lead

Abbreviations: Bcc, Burkholderia cepacia complex; BCESM, B. cepacia epidemic strain marker; $\mathrm{CF}$, cystic fibrosis; ECM, extracellular matrix; ET, Edinburgh-Toronto; LB, Luria broth TAA, trimeric autotransporter adhesin.

A supplementary table of primer sequences is available with the online version of this paper. to declining lung function, with necrotizing pneumonia and fatal septicaemia termed 'cepacia syndrome' (Mahenthiralingam et al., 2005). The Bcc consists of 17 related species that have been isolated from sputum of CF patients (Vanlaere et al., 2009). The virulence and transmissibility of each species are variable and $B$. cenocepacia and B. multivorans are the most dominant species isolated from CF patients (Segonds et al., 1999; Coenye et al., 2004). Based on recA gene analysis, $B$. cenocepacia has been subdivided into four subgroups, known as A, B, C and D. Subgroup A contains the Edinburgh-Toronto (ET)-12 epidemic strains, which are associated with 'cepacia syndrome' (Vandamme et al., 2003). The genome sequence of B. cenocepacia strain J2315, an ET-12 member (Vandamme et al., 2003), has been 
determined (Holden et al., 2009). Although the pathogenesis of Bcc is not well understood, a few virulence factors, such as two quorum-sensing systems (Sokol et al., 2003), iron acquisition via siderophore production (Visser et al., 2004), exopolysaccharide synthesis (Moreira et al., 2003) and a type III secretion system (Tomich et al., 2003), have been identified.

Many pathogenic bacteria, including Burkholderia, have a propensity for varying the surface molecules that interact with their hosts (Rocha \& Blanchard, 2002; Mahenthiralingam et al., 2005). A genetic mechanism mediating such phenotype variation involves repetitive DNA sequences that are known to promote genetic variability through homologous and illegitimate recombination processes (Achaz et al., 2002; Bichara et al., 2006). Homologous recombination occurs between large repetitive DNA sequences and may involve conversion or reciprocal strand exchange, duplication or deletion, thereby introducing changes in the genome (Rocha et al., 1999). Illegitimate recombination occurs between short closely spaced repetitive DNA sequences with few or no identical nucleotides (Bichara et al., 2006). These repeats are located either within ORFs, such that alteration in the length of the repeat promotes antigenic or phase variation, or within regulatory regions, where sequence change influences transcription (Saunders et al., 2000; Rocha \& Blanchard, 2002). This allows the generation of a vast repertoire of abilities by which pathogenic strains can adapt to the different microenvironments of the host and evade host immune responses.

We have searched the B. cenocepacia J2315 genome for close repetitive DNA sequences hoping to identify novel genes whose products may be involved in pathogenicity. Particular attention was given to a class of surface-exposed proteins, so-called autotransporter adhesins. These have been shown to play critical roles in processes such as cellto-cell aggregation, biofilm formation, serum resistance, and adherence to and invasion of host cells (Henderson et al., 2004). Computer-based analysis, combined with a PCR-based assay, permitted us to identify a putative virulence-adhesin cluster that has a distribution restricted to the epidemic ET-12 lineage of B. cenocepacia. Furthermore, within this unique cluster, we identified and characterized a novel trimeric autotransporter adhesin (TAA) (BCAM0224) and we suggest a potential role of this protein in the pathogenesis of epidemic isolates of the ET12 lineage of B. cenocepacia.

\section{METHODS}

DNA sequences of Burkholderia genomes. The sequences of B. cenocepacia J2315 and B. pseudomallei K96243 were taken from the Welcome Trust Sanger Institute (http://www.sanger.ac.uk/Projects/ B_cenocepacia/and http://www.sanger.ac.uk/Projects/B_pseudomallei/, respectively). The sequence of $B$. mallei ATCC23344 was taken from the J. Craig Venter Institute (http://cmr.jcvi.org/tigr-scripts/CMR/ GenomePage.cgi?database $=\mathrm{gbm})$. The search for orthologues also req- uired the use of the following genomes: B. cenocepacia PC184, B. cenocepacia AU1054, B. cenocepacia HI2424, B. vietnamiensis G4, B. dolosa AU0158, B. ambifaria AMMD, B. pseudomallei K96243, B. mallei ATCC23344, B. lata 383, B. thailandensis E264 and B. xenovorans LB400, available at Genomes Online DataBase v. 3.0 (http://www. genomesonline.org/).

\section{Whole genome analysis to identify each class of repeats}

Search for tandem repeats. Burkholderia genome sequences were processed using the Tandem Repeats Finder (TRF) version 3.21 program (Benson, 1999). The method identifies tandem repeats that are arranged in a contiguous head-to-tail fashion and was carried out using default settings.

Search for generic non-exact repeats. The search for different classes of repeats was computed using RepSeek (Achaz et al., 2007). We searched for repeats with a threshold of $P<0.001$, which prevents finding spurious repeats and gives a minimum seed length for the repeat in the range of 21-26 nt. This coincides with the minimal region of homology required for homologous recombination in Escherichia coli and Bacillus subtilis (Cohan, 1994). Repeat outputs were classified into five categories according to the relative distance and orientation between the two copies: distant direct (DD), distant inverted (DI), close direct (CD), overlap direct (OD) and close inverted $(\mathrm{CI})$.

Coding sequence prediction and annotation tools. For all categories of close repeat elements $(n=422)$, we identified their location within a gene or an intergenic region by using the Artemis interface (Rutherford et al., 2000). In the cases where no function was predicted, we carried out BLASTP searches and tried to extrapolate their putative function.

Each ORF predicted by Artemis was used to identify homologous sequences with BLASTP. Lipid attachment sites (lipobox) and signal peptide cleavage motifs were searched for using tools accessed at http://www.mrc-lmb.cam.ac.uk/genomes/dolop/dolop.htm and http://www.cbs.dtu.dk/services/SignalP/, respectively. Domains were assigned by Pfam analysis at http://www.sanger.ac.uk/Software/Pfam/. Since we were interested in repeats constraining gene sequence or expression, an intergenic repeat was only considered if located $<1000$ nt upstream from the start of a gene.

To find orthologues, we compared all proteins available on Burkholderia genomes with the B. cenocepacia J2315 putative antigens we identified in this work, filtering potential homologues using a threshold E-value in BLASTP of $10^{-15}$. Subsequently, we aligned the sequences, using the BLOSUM62 matrix (Henikoff \& Henikoff, 1992). Finally, we retained reciprocal best hits with identity $>45 \%$.

Bacterial strains and growth conditions. The 47 Burkholderia strains used are described in Table 1. Bacteria were cultured in LuriaBertani (LB) broth, with orbital agitation at 250 r.p.m., at $37^{\circ} \mathrm{C}$. When appropriate, media were supplemented with $150 \mu \mathrm{g}$ ampicillin $\mathrm{ml}^{-1}$ (for E. coli XL1-Blue) or $150 \mu \mathrm{g}$ trimethoprim $\mathrm{ml}^{-1}$ or $600 \mu \mathrm{g}$ kanamycin $\mathrm{ml}^{-1}$ (for B. cenocepacia). For B. cenocepacia K56-2, LB medium was supplemented with $300 \mathrm{mM} \mathrm{NaCl}$ and $10 \mathrm{mM} \mathrm{H}_{2} \mathrm{O}_{2}$.

DNA preparation and PCR screening. Total DNA was purified by using the DNeasy blood and tissue kit (Qiagen), according to the manufacturer's protocol. BCAM0218, BCAM0219 and BCAM0224 genes were amplified using the oligonucleotide primers F1 and R1 for the first gene, F2 and R2 for the second and F3 and R3 for the third gene (see Supplementary Table S1, available in Microbiology Online).

PCR amplification was carried out in $50 \mu \mathrm{l}$ reaction volumes, each containing $100 \mathrm{ng}$ template DNA, $0.2 \mu \mathrm{M}$ (each) primer, 
Table 1. Characteristics of the $47 \mathrm{Bcc}$ isolates examined in this study

CF-e, Strain that spread epidemically among patients with CF; $c b l A$, the cable pilus gene.

\begin{tabular}{|c|c|c|c|c|}
\hline Burkholderia cepacia PC783 & LMG 1222 & Onion, USA & $\mathrm{BCESM}^{-}, c b l A^{-}$ & J. J. LiPuma \\
\hline \multicolumn{5}{|l|}{ Burkholderia cenocepacia } \\
\hline $\mathrm{J} 2315$ & LMG 16656 & CF-e patient, UK & ET12 lineage $\mathrm{BCESM}^{+}, c b l A^{+}, \operatorname{rec} A-\mathrm{A}$ & G. Döring \\
\hline K56-2 & LMG 18863 & CF-e patient, Canada & ET12 lineage $\mathrm{BCESM}^{+}, c b l A^{+}, \operatorname{rec} A-\mathrm{A}$ & J. J. LiPuma \\
\hline BC45 & & CF-e patient, Canada & ET12 lineage $\mathrm{BCESM}^{+}, c b l A^{+}, \operatorname{rec} A-\mathrm{A}$ & D. P. Speert \\
\hline C5424 & LMG 18827 & CF-e patient, Canada & ET12 lineage $\mathrm{BCESM}^{+}, c b l A^{+}, \operatorname{rec} A-\mathrm{A}$ & D. P. Speert \\
\hline AU1054 & LMG 24506 & CF patient, USA & recA-B PHDC lineage & BCCMTM/LMG \\
\hline HI2424 & LMG 24507 & Soil, USA & recA-B PHDC lineage & BCCMTM/LMG \\
\hline LMG 18829 & $\mathrm{PC} 184$ & CF-e patient, USA & $\mathrm{BCESM}^{+}, c b l A, r e c A-\mathrm{B}$ PHDC lineage & G. Döring \\
\hline $\mathrm{MC} 0-3$ & LMG 24308 & Maize rhizosphere, USA & recA-B & BCCMTM/LMG \\
\hline LMG 16654 & $\mathrm{~J} 415$ & CF patient, UK & $\mathrm{BCESM}^{-}, c b l A$ & G. Döring \\
\hline LMG 16659 & C1394 & CF-e patient, UK & $\begin{array}{l}\text { Manchester epidemic strain } \text { BCESM }^{+} \text {, } \\
\text { cblA, recA-B }\end{array}$ & G. Döring \\
\hline LMG 18828 & C6433 & CF-e patient, Canada & $\mathrm{BCESM}^{+}, c b l A$, recA-A & G. Döring \\
\hline LMG 18830 & CEP511 & CF-e patient, Australia & $\mathrm{BCESM}^{+}, c b l A, r e c A-\mathrm{B}$ & G. Döring \\
\hline $\mathrm{R}-665$ & & CF patient, Canada & & G. Döring \\
\hline $\mathrm{R}-1445$ & & CF patient, Canada & & G. Döring \\
\hline $\mathrm{R}-1448$ & & CF patient, Canada & & G. Döring \\
\hline R-1449 & & CF patient, Canada & & G. Döring \\
\hline $\mathrm{R}-1471$ & & CF patient, Canada & & G. Döring \\
\hline $\mathrm{R}-4194$ & & & & G. Döring \\
\hline R-6116 & & CF patient, Canada & & G. Döring \\
\hline Burkholderia vietnamiensis PC259 & LMG 18835 & CF patient, USA & $\mathrm{BCESM}^{-}, c b l A$ & J. J. LiPuma \\
\hline Burkholderia dolosa AU0645 & LMG 18943 & CF patient, USA & & J. J. LiPuma \\
\hline Burkholderia ambifaria HI 2468 & &,- USA & & J. J. LiPuma \\
\hline Burkholderia anthinia AU1293 & LMG 21821 & CF patient, USA & & J. J. LiPuma \\
\hline Burkholderia pyrrocinia $\mathrm{BC} 011$ & LMG 21823 & Water, USA & & J. J. LiPuma \\
\hline Burkholderia ubonensis LMG 20358 & & Surface soil, Thailand & & BCCMTM/LMG \\
\hline Burkholderia latens LMG 24064 & & CF patient, Italy & & BCCMTM/LMG \\
\hline Burkholderia diffusa LMG 24065 & & CF patient, USA & & BCCMTM/LMG \\
\hline Burkholderia arboris LMG 14939 & & CF patient, Belgium & & G. Döring \\
\hline Burkholderia seminalis LMG 24067 & & CF patient, USA & & BCCMTM/LMG \\
\hline Burkholderia metallica LMG 24068 & & CF patient, USA & & BCCMTM/LMG \\
\hline Burkholderia contaminans R-10269 & LMG 23250 & CF patient, Belgium & & G. Döring \\
\hline Burkholderia lata 383 & LMG 22485 & Forest soil, Trinidad & & G. Döring \\
\hline Burkholderia phymatum STM815 & & Soil, - & & G. Döring \\
\hline Burkholderia phytofirmans PsJN & & Onion roots, - & & G. Döring \\
\hline
\end{tabular}

$0.2 \mathrm{mM}$ (each) deoxynucleoside triphosphates, $1.5 \mathrm{mM} \mathrm{MgSO}_{4}, 2.5$ U Platinium Taq DNA polymerase (Invitrogen) and $1 \times$ PCR amplification buffer. Amplification was carried out as follows: initial denaturation at $95{ }^{\circ} \mathrm{C}$ for $2 \mathrm{~min}, 25$ cycles of $45 \mathrm{~s}$ at $95{ }^{\circ} \mathrm{C}$ for denaturation, $30 \mathrm{~s}$ at $60{ }^{\circ} \mathrm{C}$ for primer annealing and $60 \mathrm{~s}$ at $68{ }^{\circ} \mathrm{C}$ for extension, with a final 7 min extension at $72{ }^{\circ} \mathrm{C}$. 
Amplification of the B. cepacia epidemic strain marker (BCESM) (esmR gene) was also performed by using the BCESM1 and BCESM2 primers (Mahenthiralingam et al., 1997) (see Supplementary Table S1). PCR conditions consisted of denaturation at $95{ }^{\circ} \mathrm{C}$ for $30 \mathrm{~s}$, annealing at $63{ }^{\circ} \mathrm{C}$ for $30 \mathrm{~s}$ and extension at $72{ }^{\circ} \mathrm{C}$ for $60 \mathrm{~s}$ for 30 amplification cycles.

Quantitative real-time PCRs. B. cenocepacia K56-2 was grown in $\mathrm{LB}$ media containing $\mathrm{NaCl}(300 \mathrm{mM})$ and $\mathrm{H}_{2} \mathrm{O}_{2}(10 \mathrm{mM})$ (initial $\left.\mathrm{OD}_{640} 0.2\right)$ for $17 \mathrm{~h}$ at $37{ }^{\circ} \mathrm{C}, 60$ r.p.m., in 24-well polystyrene microplates under microaerophilic conditions ( $<5 \%$ oxygen). Total RNA was isolated from cells harvested at late-exponential phase of growth using the RNeasy mini kit (Qiagen) following the manufacturer's protocol and RNA was treated with DNase (Qiagen) for $30 \mathrm{~min}$ at room temperature. cDNA was synthesized from $150 \mathrm{ng}$ total RNA in $10 \mu \mathrm{l}$ mixtures containing $2.5 \mu \mathrm{M}$ random hexamers, $1 \times$ PCR amplification buffer, $500 \mu \mathrm{M}$ (each) deoxynucleoside triphosphates, $0.4 \mathrm{U}$ RNase inhibitor $\mu \mathrm{l}^{-1}, 1.25 \mathrm{U}$ multiscribe reverse transcriptase $\mu \mathrm{l}^{-1}$ (Applied Biosystems, Roche). cDNA (25 ng) was used to perform quantitative real-time PCR of BCAM0224 using the Applied Biosystems 7500 Real-Time PCR system and Power SYBR Green master mix reagents, along with RT1 and RT2 primers (Supplementary Table S1). The melting curves were performed in triplicate with the following parameters: $95{ }^{\circ} \mathrm{C}$ for $10 \mathrm{~min}$, followed by 40 PCR cycles consisting of $95{ }^{\circ} \mathrm{C}$ for $15 \mathrm{~s}$ and $60{ }^{\circ} \mathrm{C}$ for $1 \mathrm{~min}$. Relative quantification of BCAM0224 gene expression was calculated by using the $\Delta \Delta \mathrm{C}_{\mathrm{T}}$ method (Livak \& Schmittgen, 2001) for B. cenocepacia K56-2 growth in LB supplemented medium compared with LB medium as control sample. The sigma factor gene sigA (BCAL0918) was used as normalization gene and amplified using RT3 and RT4 primers (see Supplementary Table S1)

\section{Cloning BCAM0224 and constructing a B. cenocepacia deletion mutant. A 1950 bp fragment of the BCAM0224 gene from B. cenocepacia K56-2 was amplified by PCR using primers F4 and R4 (see Supplementary Table S1), which contain BamHI and HindIII restriction sites, respectively. This fragment was cloned into the suicide vector pDrive (Qiagen) to generate $\mathrm{pDM} 1$. The trimethoprim resistance cassette was excised from pUC-Tp and cloned into the pDM1 BCAM0224 PstI restriction site, resulting in pDM2. This plasmid was transformed into B. cenocepacia K56-2 by electroporation and transformants were selected by growth on LB agar supplemented with $150 \mu \mathrm{g}$ trimethoprim $\mathrm{ml}^{-1}$ for $48 \mathrm{~h}$ at $37^{\circ} \mathrm{C}$. To distinguish between single- and double-crossover mutants, trimethoprim-resist- ant colonies were screened by replica plate cloning for kanamycin sensitivity. The candidate insertion mutants were further character- ized by PCR using primers F4 and R4, which allowed the BCAM0224- deficient B. cenocepacia K56-2 to be identified.}

Adherence assays. To analyse the ability of the BCAM0224 protein to interact with extracellular matrix (ECM) proteins, such as collagen type I, fibronectin and laminin, 96-well polystyrene microplates were coated with $10 \mu \mathrm{g} \mathrm{ml}^{-1}$ of each ECM protein in TBS $(137 \mathrm{mM} \mathrm{NaCl}$, $2.7 \mathrm{mM} \mathrm{KCl}, 25 \mathrm{mM}$ Tris base, $\mathrm{pH}$ 7.4) at $4{ }^{\circ} \mathrm{C}$ overnight. Cultures of B. cenocepacia K56-2 and the mutant strain $\triangle B C A M 0224$ (initial $\mathrm{OD}_{640}$ 0.2) were grown for $17 \mathrm{~h}$ at $37{ }^{\circ} \mathrm{C}, 60$ r.p.m., in microaerophilic conditions. Cells were harvested, washed with TBS and resuspended in TBS to $10^{6}-10^{7}$ cells $\mathrm{ml}^{-1}$. Equal amounts $(200 \mu \mathrm{l})$ were added to the ECM-coated wells. After incubation for $2 \mathrm{~h}$ at room temperature, non-bound bacteria were removed and adherent bacteria were fixed with $4 \%(\mathrm{w} / \mathrm{v})$ paraformaldehyde for $20 \mathrm{~min}$ and stained with $1 \%(\mathrm{w} / \mathrm{v})$ crystal violet for $10 \mathrm{~min}$. After washing with TBS, the bound crystal violet was dissolved in $95 \%$ ethanol and the absorbance was measured at $595 \mathrm{~nm}$. The experiment was repeated independently three times.
We also examined adhesion of the E. coli BL21 strain expressing the gene BCAM0224, and the empty expression vector as a control, to collagen type I. BCAM0224 was amplified by PCR from B. cenocepacia K56-2 DNA using primers BCAM0224F6 and BCAM0224R6, containing NdeI and BamHI restriction sites, respectively (Supplementary Table S1). The PCR product was digested and ligated into pET-23a vector (which resulted in pDM4), and introduced into E. coli BL21 (DE3) by electroporation. To overexpress BCAM0224, cells were grown to mid-exponential phase at $37^{\circ} \mathrm{C}$, induced by addition of $1 \mathrm{mM}$ IPTG and incubated for an additional $4 \mathrm{~h}$ at $37^{\circ} \mathrm{C}$. E. coli BL21 (DE3) transformed with the vector pET-23a was used as a control. E. coli adherence to collagen type I was performed as described for Burkholderia adherence assays.

Galleria mellonella killing assay. Cultures of B. cenocepacia K56-2 and the mutant strain $\triangle B C A M 0224$ (initial $\mathrm{OD}_{640} 0.2$ ) were grown for $17 \mathrm{~h}$ at $37^{\circ} \mathrm{C}, 60$ r.p.m., in microaerophilic conditions. Cells were then harvested and resuspended in a series of 10 -fold serial dilutions containing $10^{6}-10^{4}$ bacteria in $10 \mathrm{mM} \mathrm{MgSO}_{4}$ plus $1.2 \mathrm{mg}$ ampicillin $\mathrm{ml}^{-1}$. A micrometer was adapted to control the injection volume of a micro-syringe. This apparatus was used to inject $3.5 \mu \mathrm{l}$ aliquots into G. mellonella via the hindmost left proleg. Control larvae were injected with $10 \mathrm{mM} \mathrm{MgSO}_{4}$ plus $1.2 \mathrm{mg}$ ampicillin $\mathrm{ml}^{-1}$. Following injection, larvae were placed in glass Petri dishes and stored in the dark at $37{ }^{\circ} \mathrm{C}$. The survival and appearance was recorded at $24 \mathrm{~h}$ intervals until $72 \mathrm{~h}$.

Complementation of the BCAM0224-deficient B. cenocepacia K56-2. A PCR fragment carrying the complete coding sequence of BCAM0224 was amplified from B. cenocepacia K56-2 total DNA using primers BCAM0224F5 and BCAM0224R5, containing NdeI and XbaI restriction sites, respectively. This fragment was digested with NdeI and $\mathrm{XbaI}$ and ligated into similarly digested pDA17 under control of the constitutive $d h f r$ promoter (D. Aubert and M. A. Valvano, unpublished data), before transformation into E. coli DH5 $\alpha$ supplemented with $25 \mu \mathrm{g}$ tetracycline $\mathrm{ml}^{-1}$. The resulting replicative plasmid, pDM3, was introduced into the BCAM0224 mutant by electroporation; trans-complementation was assessed by plate adherence assay.

Statistical analysis. Relative comparisons were done between corrected values with ANOVA test for significance. A $P$-value $<0.05$ was considered statically significant. XLSTAT-Life software (Microsoft) was used to construct the Kaplan-Meier survival curves for G. mellonella infection.

\section{RESULTS}

\section{Annotation of DNA close repeats in the $B$. cenocepacia J2315 genome sequence}

We first evaluated the number and distribution of the different classes of repeats among the three chromosomes and the plasmid that compose the B. cenocepacia J2315 genome (Table 2). The size of the repeats goes from $10 \mathrm{bp}$ to a maximum of $50068 \mathrm{bp}$, and overall we found 1056 repeats. Fig. 1 illustrates the distribution of such repeats on the genome. It should be noted that very little difference is observed in the density of repeats for each replicon (Fig. 1).

We focused our interest in the 422 close DNA repeats present in the B. cenocepacia J2315 genome. For this, we annotated these repeats and grouped them into four classes (see Methods; Table 2). Among the 422 DNA close repeats, $348(82 \%)$ are located within coding regions and $74(18 \%)$ 
Table 2. Number of elements identified in $B$. cenocepacia J2315 for each class of repeats

\begin{tabular}{|c|c|c|c|c|c|c|c|c|}
\hline \multirow{2}{*}{$\begin{array}{l}\text { B. cenocepacia } \\
\text { J2315 }\end{array}$} & \multirow{2}{*}{$\begin{array}{c}\text { Length } \\
(\mathbf{k b})\end{array}$} & \multicolumn{2}{|c|}{ Distant } & \multicolumn{4}{|c|}{ Close } & \multirow[t]{2}{*}{ Total } \\
\hline & & DD & DI & CD & OD & $\mathrm{CL}$ & $\mathbf{T}$ & \\
\hline Chromosome 1 & 3870 & 165 & 165 & 13 & 52 & 2 & 82 & 480 \\
\hline Chromosome 2 & 3271 & 157 & 110 & 54 & 79 & 3 & 50 & 453 \\
\hline Chromosome 3 & 876 & 22 & 10 & 18 & 43 & 0 & 14 & 107 \\
\hline Plasmid & 93 & 3 & 2 & 4 & 4 & 3 & 0 & 16 \\
\hline
\end{tabular}

are in putative promoter regions. As a consequence, illegitimate and homologous recombination among close repetitive DNA will predominantly affect coding sequences.

In order to identify potential virulence factors on the $B$. cenocepacia J2315 genome, we examined the length and number of repeats, as well as the annotation of the 422 DNA close repeats. Among the 422 DNA close repeats, 45 genes potentially involved in virulence were identified and grouped into 12 functional classes (Table 3). Of the 45 genes selected, 28 were located in chromosome 1, 10 in chromosome 2, six in chromosome 3 and one in the plasmid (Table 3). A total of 41 repeat elements are located within coding regions and the remaining four are within putative promoters, where they could influence transcription (Table 3).

Of the 45 genes evaluated, 13 were included into the putative antigens class and are strong candidates for surface-exposed phase variable genes (Table 4). Overall, this set of genes presents the largest density of repeats in the sorted list of the 422 DNA close repeats and it was selected for further study. Hence, we have made an analysis of the existence of orthologues of the B. cenocepacia J2315 antigens subset in other Burkholderia genomes. Of the 13 gene products selected, four (BCAL0340, BCAL1524, BCAM2418 and BCAS0236) were found to have length variation in the gene products, due to differences in the numbers of coding tandem repeats. Notably, the putative antigens BCAM0219 and BCAM0223, annotated as TAAs, are absent from the other genomes (Table 4).

\section{BCAM0219 and BCAM0223 belong to a putative adhesin cluster that has a distribution restricted to the ET-12 lineage of $B$. cenocepacia}

The putative TAAs BCAM0219 and BCAM0223, may be part of an unstable genomic region. Therefore, we compared the corresponding region of the B. cenocepacia J2315 chromosome 2 with the genome sequence of strain $B$. cenocepacia AU1054. The two adhesin genes are part of an approximately $142 \mathrm{~kb}$ genomic region which is lacking in the strain B. cenocepacia AU1054 (Fig. 2). As shown in Fig. 2(b), BCAM0219 and BCAM0223 are members of a putative adhesin cluster (designated BuceJ2315_pac) located downstream of the previously identified B. cenocepacia J2315 cci island, which includes the BCESM, an epidemiological marker for virulent $B$. cenocepacia strains (Baldwin et al., 2004). This cluster is approximately $24 \mathrm{~kb}$ and is putatively organized with four adhesins
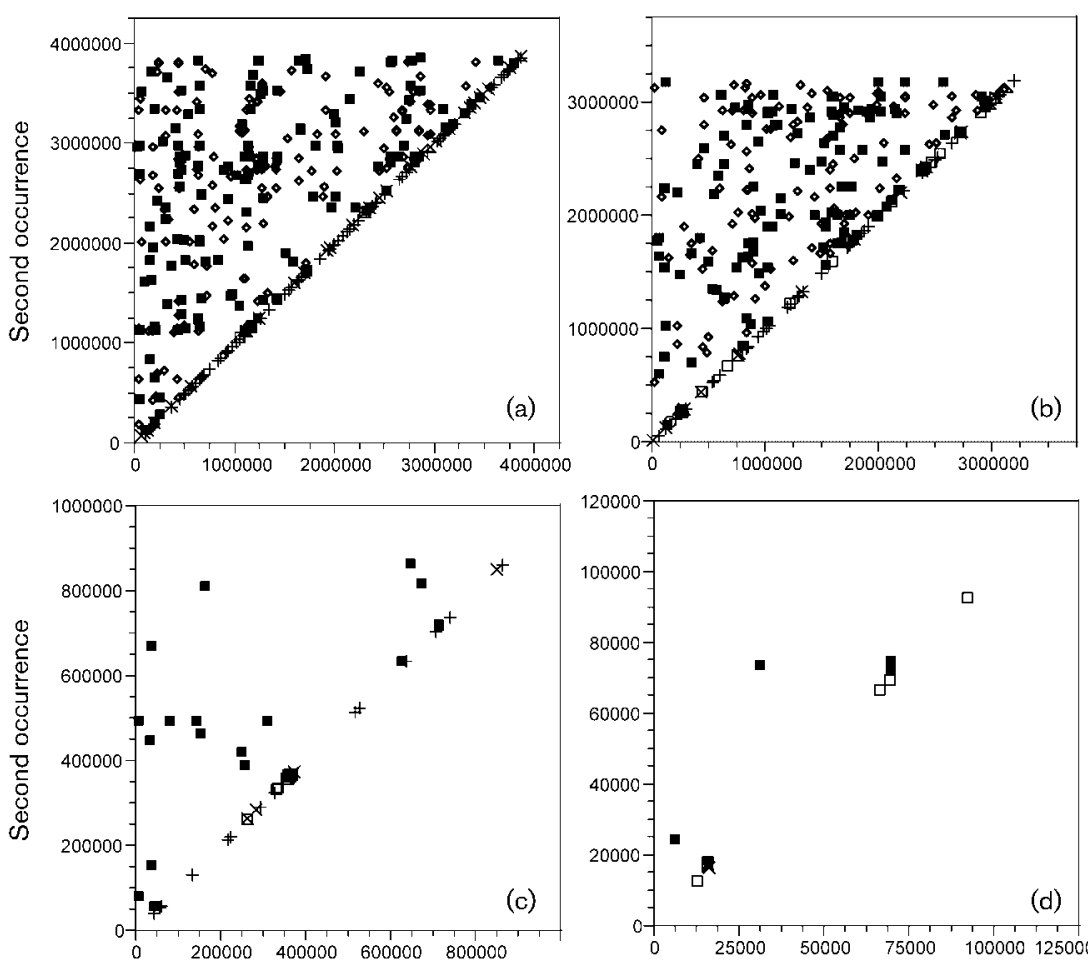

First occurrence

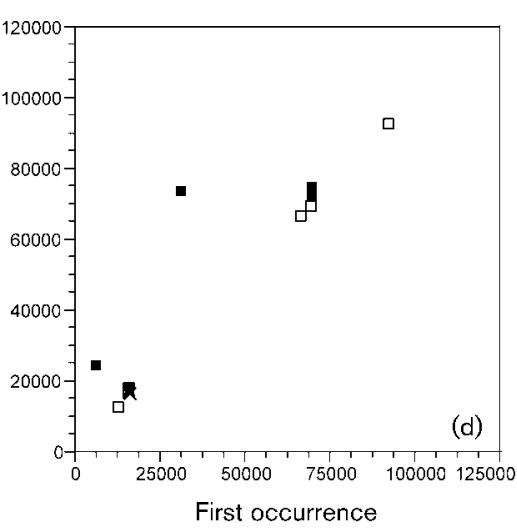

Fig. 1. Distribution of close repeats among the three chromosomes and the plasmid of $B$. cenocepacia J2315. (a) Chromosome 1 (3.9 Mbp), (b) chromosome 2 (3.2 Mbp), (c) chromosome $3(0.9 \mathrm{Mbp})$ and (d) plasmid (92.7 kbp). The density of repeats were 0.12 (a) and (c), 0.14 (b), and 0.17 (d). Repeats were assigned to one of six classes: DD, distant direct $(\mathbf{\square})$; DI, distant inverse $(\diamond)$; CD, close direct $(\square)$; OD, overlap direct $(x) ; \mathrm{Cl}$, close inverse $(\triangle) ; T$, tandem $(+)$. The $x$-axis represents the position of the first occurrence of the repeat in the genome and the $y$-axis represents the position of the second occurrence. 
(BCAM0219, 0223, 0224 and 0225), one outer-membrane protein (BCAM0220), one sensor histidine kinase (BCAM0218) and two regulators (BCAM0221 and 0222) (Fig. 2b). The BuceJ2315_pac is surrounded by DNA segments with a very low $\mathrm{G}+\mathrm{C}$ content (Fig. $2 \mathrm{~b}$ and $\mathrm{c}$ ). In addition to the BuceJ2315_pac cluster, the genomic region also includes the previously reported $B$. cenocepacia pathogenicity island $c c i$ (Baldwin et al., 2004) among 123 predicted coding sequences (Fig. 2).

\section{A PCR approach to study the distribution of the adhesin locus among Bcc clinical isolates}

PCR analysis based on three members of the putative adhesin locus (one sensor histidine kinase, BCAM0218, and two TAAs, BCAM0219 and BCAM0224) was performed to verify the presence of the selected genes among a panel of 47 strains representing the 17 species of the Bcc. The majority of clinical isolates examined ( 29 out 47 ) were B. cenocepacia strains, since this is the major species isolated from patients with CF. Two species outside the Bcc were included as controls (Table 1). These three genes were found exclusively in B. cenocepacia isolates (Fig. 3), except for BCAM0219 (also found in B. arboris LMG 14939). Of these, the three genes were amplified from the isolates representing the highly transmissible ET-12 lineage, while no products were amplified from the other members of $B$. cenocepacia species, except for gene BCAM0218 (strains Buce AU12250, Buce LMG 13013 and Buce R-1445) and gene BCAM0219 (strain Buce R-1449). The BCAM0224 gene was exclusively detected in B. cenocepacia ET-12 lineage (Fig. 3). We also analysed the prevalence of BCESM, a $1.4 \mathrm{~kb}$ sequence containing an ORF with homology to transcriptional regulatory genes $(e s m R)$, which is a previously described marker for transmissible Burkholderia strains (Mahenthiralingam et al., 1997). All ET-12 isolates contained both the adhesin genes and BCESM, although other epidemic and non-epidemic B. cenocepacia isolates containing the BCESM, but lacking the adhesin genes, were also observed (Fig. 3). Furthermore, the proposed PCR-based assay using

(c) GC content

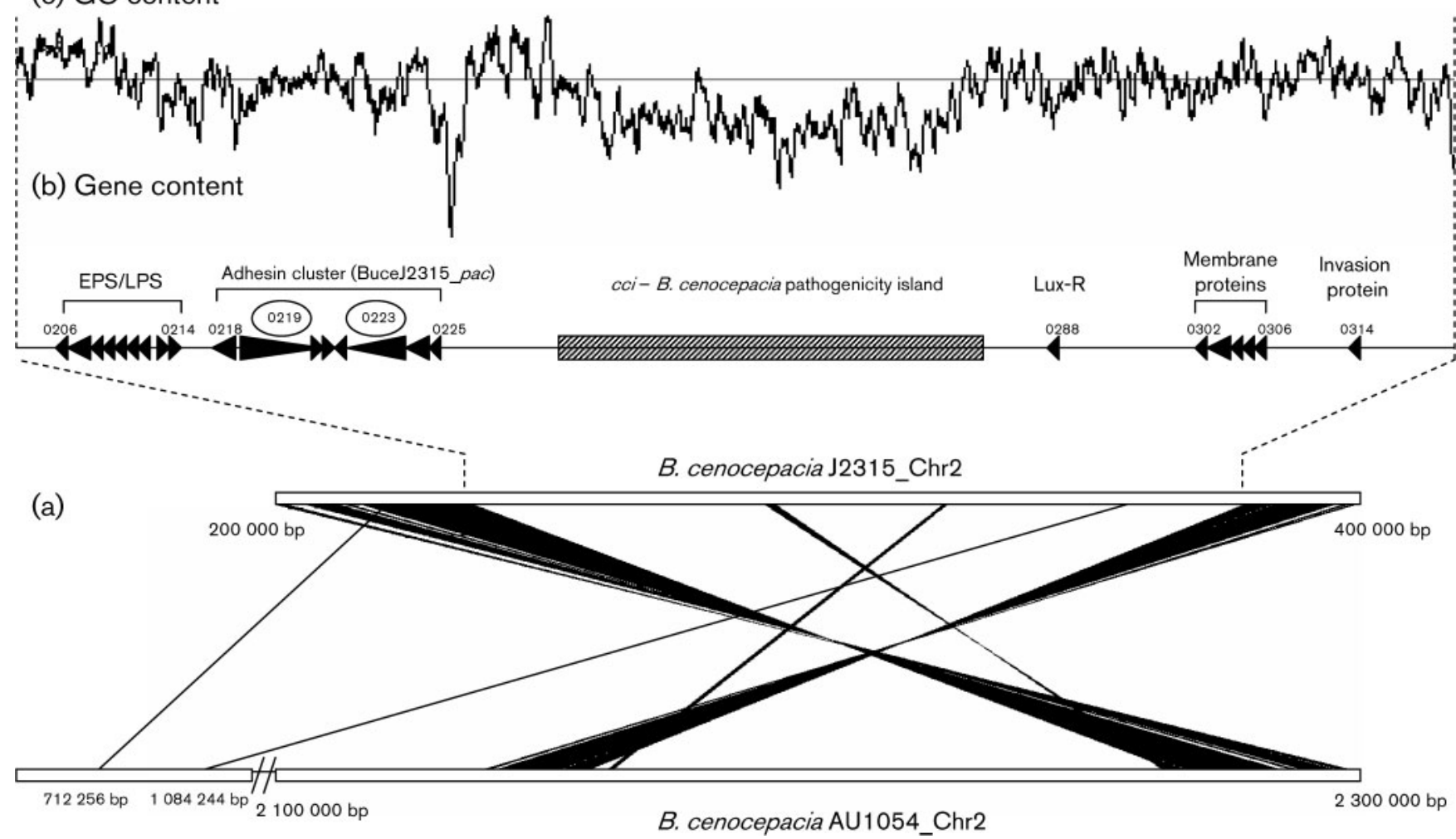

Fig. 2. (a) Part of B. cenocepacia J2315_Chromosome 2 and B. cenocepacia AU1054_Chromosome 2 visualized with the WebACT tool (http://www.webact.org/WebACT/home), which enabled the visualization of TBLASTX (threshold E-value of 0.001 using the BLOSUM62 matrix) comparisons between the sequences. The defined $142 \mathrm{~kb}$ genomic region of $B$. cenocepacia $\mathrm{J} 2315$ is absent in $B$. cenocepacia AU1054. This region (b) of 123 predicted coding sequences includes the putative adhesin cluster (BuceJ2315_pac), the reported BCESM (cci island) described by Baldwin et al. (2004), a cluster of genes presumably involved in exopolysaccharide or lipopolysaccharide synthesis, genes encoding membrane proteins, and an invasion protein. BCAM0219 and BCAM0223 are circled. (c) The GC content of the region being studied is shown. The line at $67.2 \%$ indicates the overall $\mathrm{G}+\mathrm{C}$ content estimated for the B. cenocepacia J2315 chromosome 2. 
Table 3. Virulence functions encoded in the $B$. cenocepacia J2315 genome associated with DNA close repeats

\begin{tabular}{|c|c|c|c|c|}
\hline Virulence trait & Chromosome/plasmid & $\begin{array}{r}\text { Class of repeat/ } \\
\text { position (nt) }\end{array}$ & Location $^{\star}$ & Gene product/position (nt) \\
\hline \multirow[t]{2}{*}{ Bacteriophages } & Chr_1 & $\mathrm{T} / 105818-105846$ & G & Hypothetical phage protein/105813-106028 c \\
\hline & Chr_1 & OD/115833-115842 & G & Tail fibre assembly protein/115768-116502 c \\
\hline Type III secretion & Chr_1 & $\mathrm{T} / 576538-576560$ & G & $\begin{array}{l}\text { Putative FliI inhibitor involved in flagella } \\
\text { biosynthesis/575949-576632 c }\end{array}$ \\
\hline \multirow[t]{2}{*}{ Chemotaxis } & Chr_1 & $\mathrm{T} / 154322-154341$ & G & $\begin{array}{l}\text { Methyl-accepting chemotaxis protein/153107- } \\
155065\end{array}$ \\
\hline & Chr_2 & $\mathrm{CD} / 761505-762229$ & G & $\begin{array}{l}\text { Methyl-accepting chemotaxis protein/760326- } \\
763373\end{array}$ \\
\hline \multirow[t]{2}{*}{ Pilus biogenesis } & Chr_1 & $\mathrm{T} / 3857610-3857635$ & G & $\begin{array}{l}\text { General secretory pathway protein J (type-4 pili)/ } \\
3856969-3857640 \mathrm{c}\end{array}$ \\
\hline & Chr_3 & $\mathrm{CD} / 334436-334768$ & I & Pilus subunit protein/334465-334656 \\
\hline \multirow[t]{5}{*}{ Enzymes } & Chr_1 & $\mathrm{T} / 1500582-1500597$ & G & Hypothetical lipoprotein/1500364-1500843 \\
\hline & Chr_1 & OD/2437210-2437545 & G & $\begin{array}{l}\text { Dihydrolipoamide acetyltransferase E2/2436248- } \\
2437891 \text { c }\end{array}$ \\
\hline & Chr_1 & $\mathrm{T} / 3047958-3047982$ & G & $\begin{array}{l}\text { Putative } N \text {-acetylmuramoyl-L-alanine amidase/ } \\
3047221-3048735\end{array}$ \\
\hline & Chr_1 & OD/3865585-3865594 & G & Lytic transglycosylase/3865151-3865645 \\
\hline & Chr_2 & $\mathrm{CD} / 2384780-2388173$ & G & $\begin{array}{l}\text { Putative haemolysin-related protein/2383411- } \\
2392185 \text { c }\end{array}$ \\
\hline \multirow{5}{*}{$\begin{array}{l}\text { Multidrug resistance } \\
\text { transporters }\end{array}$} & Chr_1 & $\mathrm{CD} / 1171539-1174656$ & G & Putative membrane protein/1170559-1173867 c \\
\hline & Chr_1 & $\mathrm{T} / 1670177-1670191$ & G & $\begin{array}{l}\text { Putative multidrug resistance protein B/1669180- } \\
1670739 \text { c }\end{array}$ \\
\hline & Chr_1 & $\mathrm{T} / 3049868-3049890$ & I & Putative permease protein/3048781-3049659 c \\
\hline & Chr_1 & $\mathrm{T} / 3096355-3096373$ & G & Outer membrane efflux protein/3095788-3097311 c \\
\hline & Chr_3 & $\mathrm{T} / 860050-860068$ & G & Outer membrane efflux protein/859513-861015 c \\
\hline \multirow[t]{11}{*}{ Transporters } & Chr_1 & OD/65748-65763 & I & $\begin{array}{l}\text { Putative heavy metal resistance membrane ATPase/ } \\
65909-68044\end{array}$ \\
\hline & Chr_1 & $\mathrm{T} / 1850184-1850212$ & G & $\begin{array}{l}\text { Putative iron transport-related membrane protein/ } \\
1849348-1851438\end{array}$ \\
\hline & Chr_1 & $\mathrm{T} / 1977907-1977923$ & G & $\begin{array}{l}\text { Putative iron-transport related protein/1977502- } \\
1978209 \mathrm{c}\end{array}$ \\
\hline & Chr_1 & $\mathrm{CD} / 2321739-2322591$ & G & Putative ABC transporter/2321263-2323194 \\
\hline & Chr_1 & $\mathrm{T} / 3081628-3081656$ & G & $\begin{array}{l}\text { Putative transmembrane ABC transporter/3080773- } \\
3081726 \text { c }\end{array}$ \\
\hline & Chr_1 & $\mathrm{T} / 3191355-3191374$ & G & $\begin{array}{l}\text { Putative proline-rich exported protein/3190341- } \\
3192869\end{array}$ \\
\hline & Chr_1 & $\mathrm{T} / 3324221-3324244$ & G & $\begin{array}{l}\text { Probable outer-membrane lipoprotein/3323592- } \\
3324281 \text { c }\end{array}$ \\
\hline & Chr_2 & $\mathrm{T} / 2224050-2224074$ & G & $\begin{array}{l}\text { Putative iron transport receptor protein/2223574- } \\
2225817\end{array}$ \\
\hline & Chr_2 & $\mathrm{T} / 2643585-2643607$ & G & $\mathrm{ABC}$ transporter/2642737-2643696 \\
\hline & Chr_3 & $\mathrm{CD} / 358949-360023$ & G & Autotransporter/357936-370640 \\
\hline & Chr_3 & $\mathrm{T} / 636485-636507$ & G & HlyD family secretion protein/636385-637803 \\
\hline Quorum sensing & Chr_1 & TR/1627906-1627920 & G & $\begin{array}{l}\text { Putative LuxR-family regulatory protein/1627670 } \\
1628236 \text { c }\end{array}$ \\
\hline Transcriptional factors & Chr_1 & OD/3752632-3752862 & G & Histone H-1 like protein/3752545-3753195 c \\
\hline EPS/LPS & Chr_1 & $\mathrm{T} / 2028960-2028978$ & G & Glycosyltransferase/2028519-2029727 c \\
\hline \multirow[t]{5}{*}{ Putative antigens } & Chr_1 & $\mathrm{T} / 159960-159985$ & G & BCAL 0138 lipoprotein/159881-161119 \\
\hline & Chr_1 & $\mathrm{T} / 366721-366739$ & G & BCAL 0340 lipoprotein/366232-366858 \\
\hline & Chr_1 & OD/1688274-1688355 & G & BCAL 1524 lipoprotein/1688158-1689831 c \\
\hline & Chr_1 & $\mathrm{CD} / 3442677-3443954$ & G & $\begin{array}{l}\text { BCAL } 3154 \text { putative glycine-rich surface protein/ } \\
3442386-3445307 \text { c }\end{array}$ \\
\hline & Chr_1 & $\mathrm{T} / 3695870-3695899$ & G & BCAL 3372 lipoprotein/3695865-3696416 c \\
\hline
\end{tabular}


Table 3. cont.

\begin{tabular}{|c|c|c|c|c|}
\hline & Chr_2 & $\mathrm{CD} / 260745-266200$ & G & $\begin{array}{l}\text { BCAM } 0219 \text { autotransporter adhesin /259271- } \\
268030\end{array}$ \\
\hline & Chr_2 & $\mathrm{CD} / 272057-274176$ & G & $\begin{array}{l}\text { BCAM } 0223 \text { autotransporter adhesin /270927- } \\
275579 \text { c }\end{array}$ \\
\hline & Chr_2 & $\mathrm{CD} / 2723836-2729959$ & G & $\begin{array}{l}\text { BCAM } 2418 \text { cell surface membrane protein; } \\
\text { haemagglutinin motif/2722300-2730627 }\end{array}$ \\
\hline & Chr_3 & $\mathrm{CD} / 260121-260829$ & G & BCAS 0236 glycine-rich protein/258387-262877 \\
\hline & Chr_3 & OD/280643-280650 & I & BCAS 0251 lipoprotein/279266-280423 c \\
\hline & Plasmid & $\mathrm{CD} / 15829-17872$ & G & pBCA 011 adhesin/15126-20077 c \\
\hline Siderophores & Chr_2 & $\mathrm{T} / 2492631-2492645$ & G & Pyochelin synthetase/2491217-2496699 c \\
\hline
\end{tabular}

${ }^{*} \mathrm{G}$ or I indicate that the repeat falls within a gene or between two genes, respectively.

the set of primers for BCAM0224 could be used as a valuable tool to discriminate among $B$. cenocepacia epidemic clones belonging to the ET-12 lineage.

\section{B. cenocepacia BCAM0224 is a trimeric autotransporter adhesin required for cell adhesion and virulence}

A BLASTP search revealed that BCAM0224 has high amino acid homology with the prototype member of the trimeric autotransporter family of surface-attached oligomeric proteins, the Yersinia adhesin YadA, defined by the domain Pfam 03895 (Hoiczyk et al., 2000). To confirm our prediction, we also used the daTAA program, which is a web-based tool that annotates domains of trimeric auto- transporter adhesins (http://toolkit.tuebingen.mpg.de/dataa) (Szczesny \& Lupas, 2008). BCAM0224 is 953 aa long, with a calculated molecular mass of $90 \mathrm{kDa}$. Like the other TAA proteins, BCAM0224 has a head-stalk-anchor modular organization (Fig. 4a). Analysis of the BCAM0224 amino acid sequence using InterPro (http://www.ebi.ac.uk/ interpro/) revealed significant hits for the presence of seven clusters of Hep_Hag (Pfam domain PF05658), six clusters of HIM (Pfam domain PF05662) and two collagenbinding domains (Pfam domain PF01391) (Fig. 4a). Hep_Hag and HIM are short repeat motifs found in many bacterial invasins and haemagglutinins (Valle et al., 2008). Using the daTAA program, we also predict the presence of an extended signal sequence with a predicted cleavage site between amino acids 1 and 43 (Fig. 4a).

Table 4. Proteins of the 11 finished/unfinished Burkholderia genomes available that belong to the putative antigens class, listed according to orthology relationships

$\checkmark$, Orthologue present; $\times$, orthologue absent; LV, orthologue associated with length variation.

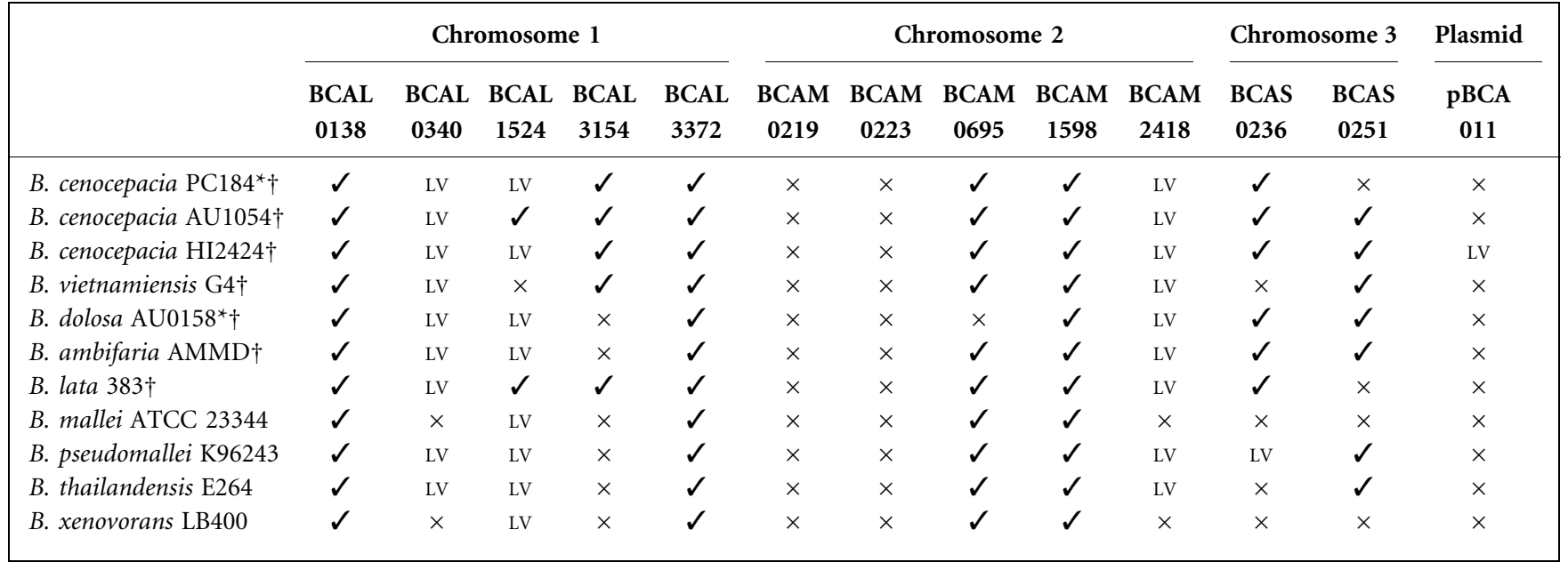

*Unfinished genome sequence (July 2009).

$\dagger$ Bcc strains. 

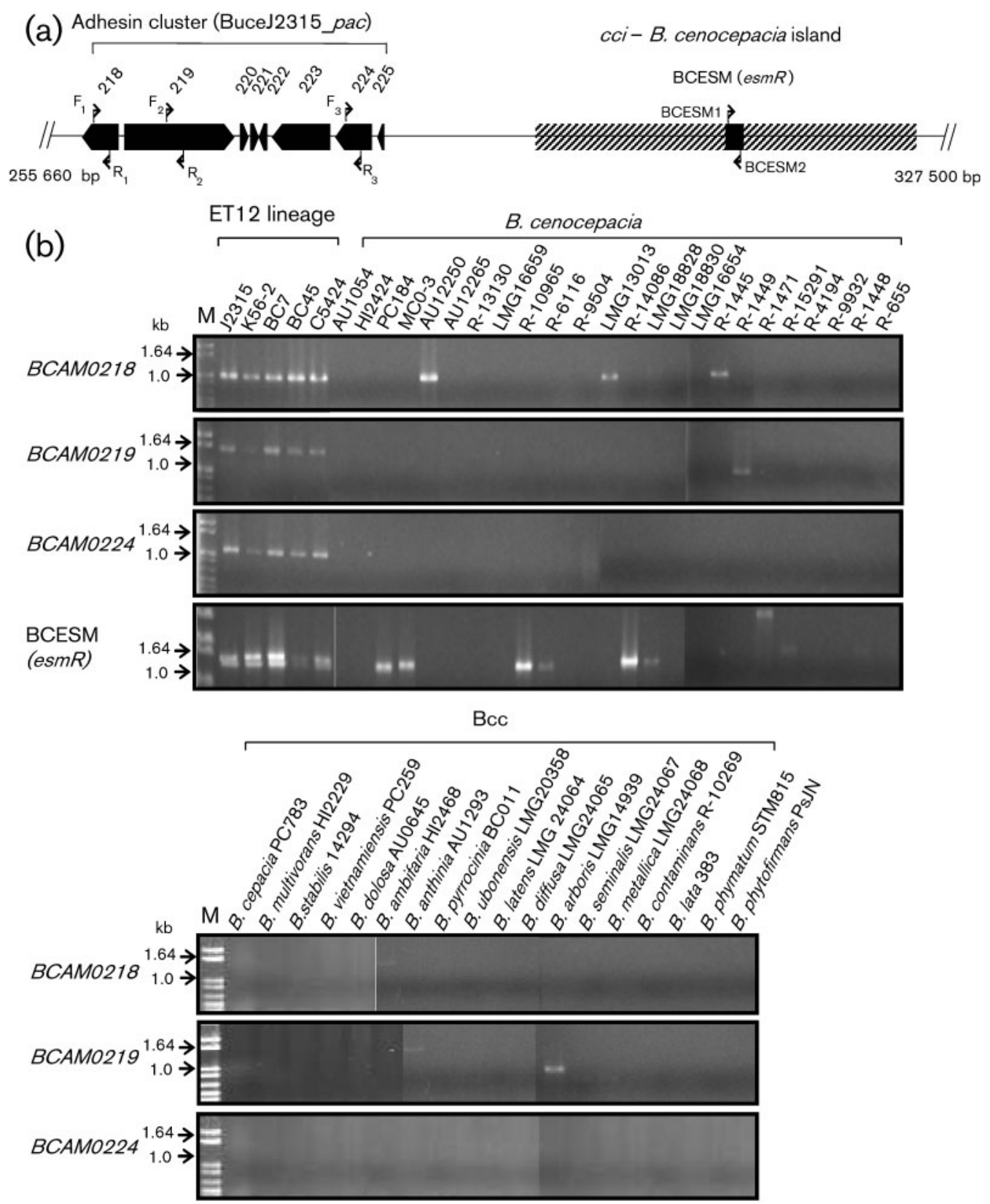

Fig. 3. (a) Genetic organization of the putative adhesin cluster (BuceJ2315_pac). Arrows show the direction of gene transcription. Positions of the PCR primers used to amplify BCAM0218 (F1, R1), BCAM0219 (F2, R2), BCAM0224 (F3, R3) and $B C E S M$ (BCESM1 and -2) genes are indicated. The $B$. cepacia cci island is also shown. (b) DNA products amplified by PCR from Burkholderia species using BCAM0218, BCAM0219, BCAM0224 and BCESM primers. The panel of Burkholderia species included 47 strains representing the 17 Bcc species. $B$. cenocepacia strains comprised the majority of clinical isolates examined (29 of 47); two species outside the Bcc (B. phymatum STM815 and B. phytofirmans PsJN) were included as controls. The BCAM0218, BCAM0219, BCAM0224 and BCESM gene products were 1002, 1553, 1130 and 1418 bp, respectively, as expected. In contrast with previously published data (Mahenthiralingam et al., 2000), BCESM was not amplified in strains LMG16659 and LMG18830. Lane M, molecular size marker (1 kb ladder).

Expression of the BCAM0224 adhesin gene was assessed by real-time PCR in $B$. cenocepacia K56-2. Interestingly, physico-chemical environmental factors similar to those that are encountered in the lung microenvironment of $\mathrm{CF}$ patients, such as high osmolarity, oxygen-limited condi- tions and oxidative stress, enhance (sevenfold induction) its expression level.

In order to evaluate the functional role of BCAM0224 we constructed a knockout mutant of B. cenocepacia K56-2 

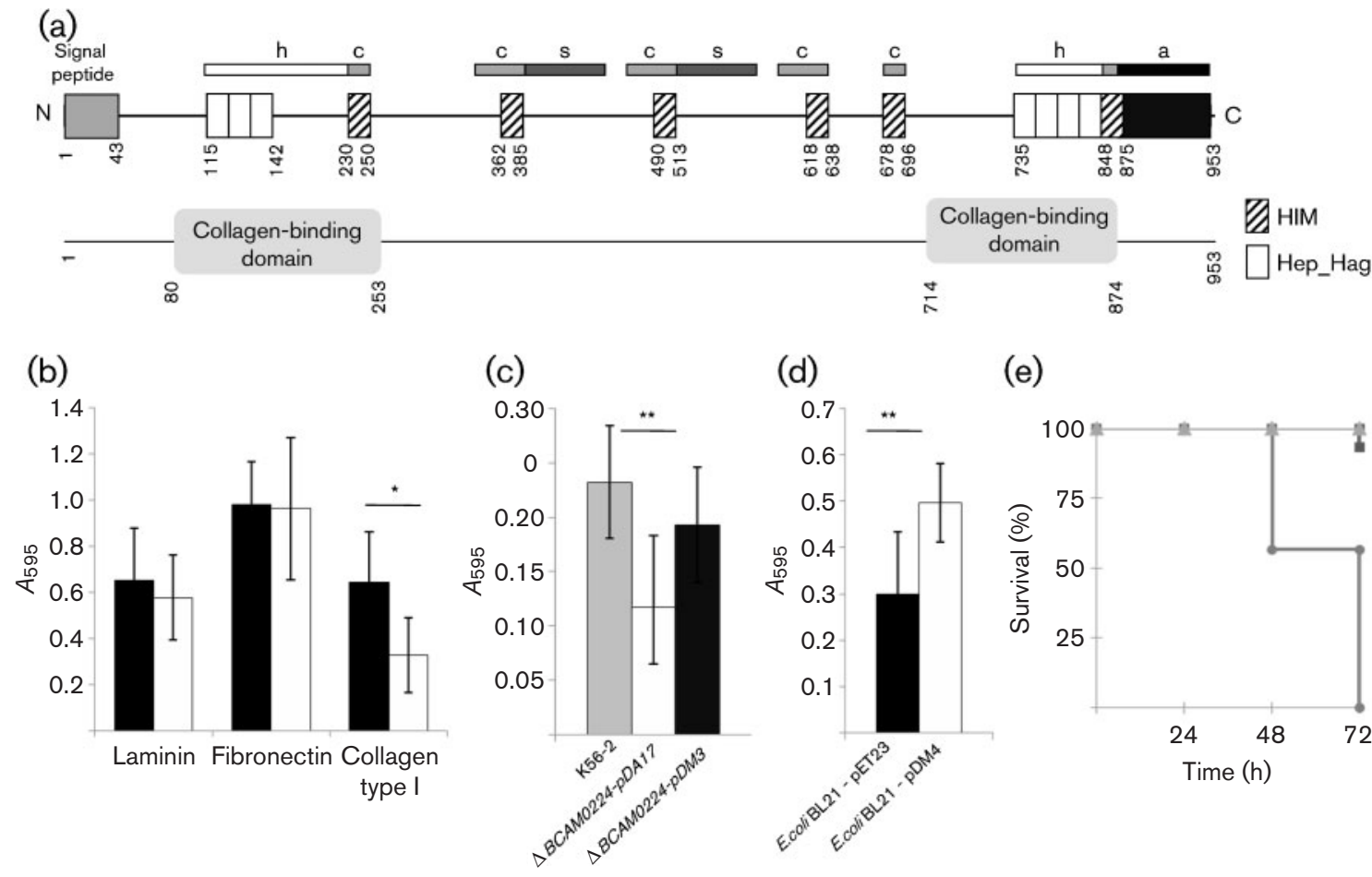

(e)

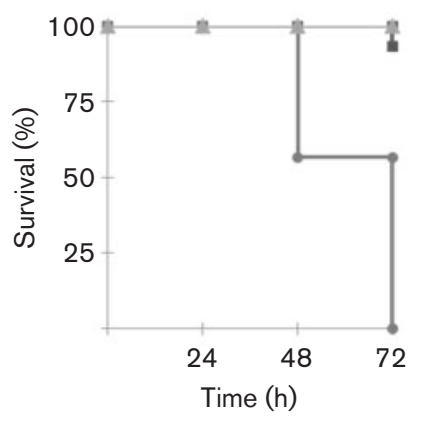

Fig. 4. (a) Schematic representation of the predicted domain organization of BCAM0224 from B. cenocepacia J2315. h, Head; c, connector; s, stalk; a, anchor. (b) Adherence of wild-type B. cenocepacia K56-2 (filled bars) and $\triangle B C A M 0224$ mutant (open bars) to laminin, fibronectin and collagen type I. The binding capacity to collagen type I was significantly decreased in the mutant $\left({ }^{\star} P<0.001\right)$. The results are from three independent experiments; bars indicate SD. (c) Adherence to collagen type I by the wildtype $B$. cenocepacia K56-2 (shaded bars), the $\triangle B C A M 0224$ mutant (open bars) and the $\triangle B C A M 0224$-complemented strain (filled bars). (d) Adherence to collagen type I by E. coli BL21 (DE3) expressing BCAM0224 (filled bars) and E. coli BL21 (DE39)/pET 23-a used as a control (open bars). In (c) and (d), a significant difference is indicated by asterisks $\left({ }^{\star \star} P<0.006\right)$. (e) Kaplan-Meier survival curves for G. mellonella infection with wild-type B. cenocepacia K56-2 (๑) and the $\triangle B C A M 0224$ mutant $(\boldsymbol{\square})$ strains and the control $(\boldsymbol{\Lambda})(P<0.005$, for comparison of the wild-type and the mutant). Ten larvae were injected with $10^{4}$ c.f.u., and larvae were scored as dead when they ceased moving, changed from their normal pale cream coloration to brown, and failed to respond when gently manipulated with a pipette tip. The results are from three independent experiments.

BCAM0224 ( $\triangle B C A M 0224)$ and examined the adherence capacity of cells to surfaces coated with various mammalian ECM proteins, such as collagen type I, fibronectin and laminin, by in vitro binding assays. Compared with the BCAM0224negative mutant, the wild-type $B$. cenocepacia K56-2 cells adhered strongly to collagen type I matrix (Fig. $4 \mathrm{~b} ; P<0.001$ ).

To confirm that the insertion of the trimethoprim cassette into BCAM0224 has no polar effect on the expression of the downstream gene BCAM0223, an in trans complementation experiment using BCAM0224 cloned in the replicative plasmid pDA17 was performed. The introduction of pDM3 recombinant plasmid into the BCAM0224 mutant showed a partial restoration of the adhesive phenotype when compared with the phenotype of B. cenocepacia K56-2 wildtype (Fig. 4c). This could be a result of the lower expression level of the BCAM0224 protein. We also examined adhesion of the E. coli BL21 strain expressing the gene BCAM0224 to collagen type I, using the empty expression vector as a control. A difference was observed between the recombinant and the vector control (Fig. 4c), indicating that BCAM0224 is a collagen-binding TAA. This result is in accordance with the trans-complementation result obtained with the $B$. cenocepacia $\triangle B C A M 0224$ mutant.

Finally, in order to test the assumption that the trimeric autotransporter BCAM0224 might somehow be involved in virulence, we compared the ability of the wild-type $B$. cenocepacia K56-2 and the $\triangle B C A M 0224$ mutant strains to cause mortality in G. mellonella (caterpillars of the greater wax moth) larvae infection assays. As shown in Fig. 4(d), the rate of mortality was dramatically reduced in larvae infected with the $\triangle B C A M 0224$ mutant compared with the wild-type K56-2. At $72 \mathrm{~h}$ post-infection, all the wild-type-infected larvae $(n=10)$ were killed, whereas $90 \%$ of larvae infected with the mutant had survived $(P<0.005)$ (Fig. $4 \mathrm{~d})$.

\section{DISCUSSION}

In this study, we carried out a global analysis of repeats in the genome of B. cenocepacia J2315, the causative agent of 
numerous fatalities in $\mathrm{CF}$ patients. We found a large number of repeats in the B. cenocepacia J2315 genome (Table 2). This observation suggests that $B$. cenocepacia J2315 has a high genome plasticity that should be important in its capacity to adapt to human and animal hosts as well as to different environments.

Among the 422 DNA close repeats, we selected a total of 45 potential genes assigned into a panel of 12 virulence functional classes (Table 3). Among the 45 genes, 34 have been previously described as virulence factors in Burkholderia strains or other bacterial pathogenic genera, such as Neisseria, Mycobacterium, Haemophilus and Vibrio. These include genes for phase-variable oligosaccharide structure of lipopolysaccharide (Hughes et al., 1997; Vinion-Dubiel \& Goldberg, 2003), siderophore production (Anderson et al., 2004; Visser et al., 2004), multidrugresistant transporters (Wigfield et al., 2002), cable pili (Sajjan et al., 2003), and intra- and extracellular enzymes, such as haemolysin and lytic transglycosylase (Cloud \& Dillard, 2002; Takahashi et al., 2004).

Among the 12 functional virulence classes that we have defined, we focused on putative antigens because the 13 gene products included within this class show the highest over-representation of close repeats and are strong candidates for surface-exposed adhesins and lipoproteins involved in antigenic response. Three interesting findings emerged from our analysis: (i) in general, the putative antigens are under-represented in B. xenovorans LB400; (ii) using each of the $B$. cenocepacia J2315 putative antigens as a reference, we found that BCAL0340, BCAL1524 and BCAM2418 have significant differences in the numbers of coding tandem repeats, and for that reason are strong candidates for novel virulence factors; and (iii) even more strikingly, BCAM0219 and BCAM0223, annotated as autotransporter adhesins, are absent from the other genomes (Table 4).

BCAM0219 and BCAM0223 genes are members of a putative adhesin cluster (BuceJ2315_pac) located downstream of the described BCESM (Baldwin et al., 2004) (Fig. 2). BuceJ2315_pac is organized in a modular fashion and contains four autotransporter adhesins genes, one outer-membrane protein, one sensor histidine kinase and two response regulator genes (Fig. 2a). We hypothesized that the periplasmic sensor histidine kinase is responsible for sensing stimuli, and a second component, the two response regulators, regulates two sets of virulence genes, namely the co-transcribed autotransporter adhesin (BCAM0219) and outer-membrane protein (BCAM0220) genes and the three autotransporter adhesins genes (BCAM0223, BCAM0224 and BCAM0225) (Fig. 2). Our analysis revealed that the BuceJ2315_pac is part of a $142 \mathrm{~kb}$ genomic region that comprises an upstream and downstream extension of the $c c i$ island previously discovered by RAPD analysis (Baldwin et al., 2004) and encoding a large number of genes linked to both virulence and metabolism (Fig. 2).
PCR assays using primers targeting three genes of the putative BuceJ2315_pac adhesin locus were designed and used to test a panel of 47 Burkholderia strains (Fig. 3). Our findings substantiate that the adhesin genes are located on a chromosomal region unique to some $B$. cenocepacia strains. We also observed that BCAM0224 is an exclusive marker of epidemic B. cenocepacia belonging to the ET-12 lineage and we therefore recommend employment of this PCR assay for discrimination of bacteria among Bcc members that belong to this virulent subgroup. These results are compatible with previous studies, which revealed the autotransporter adhesins BCAM0223 and BCAM0225 as unique in the ET-12 lineage (Bernier \& Sokol, 2005), but BCAM0223, just like $c b l A$, is present in some B. cenocepacia strains distinct from ET-12 (Turton et al., 2009).

As a potentially important surface-exposed protein from B. cenocepacia ET-12 epidemic strains, we examined BCAM0224 for several features. Bioinformatic analysis of BCAM0224 predicts that this protein is an orthologue of the surface-attached collagen-binding protein YadA from Yersinia species, the best characterized member of the TAAs (Tamm et al., 1993; Koretke et al., 2006). Other members of this class, namely NadA from Neisseria meningitidis (Comanducci et al., 2002), UspA-1 and -2 from Moraxella catarrhalis (Lafontaine et al., 2000) and BadA from Bartonella henselae (Riess et al., 2004) are important pathogenicity factors, playing critical roles in processes such as bacterial adherence, biofilm formation, serum resistance and invasion of host cells (Linke et al., 2006). They represent one of the major families of surfaceexposed proteins in Gram-negative bacteria and are organized in a modular fashion, i.e. a membrane-anchored C-terminal conserved domain that forms a trimeric $\alpha$ barrel pore (also called $\alpha$-domain) and permits, through the type $\mathrm{V}$ protein secretion pathway (T5SS), the translocation of a passenger domain (stalk and an Nterminal head) to the bacterial cell surface (Dautin \& Bernstein, 2007).

Similar to the results obtained with YadA (Heise \& Dersch, 2006), in this study, we found that BCAM0224 promotes bacterial adherence to the ECM protein collagen type I, one of the most abundant components of the ECM. This result supports our in silico analysis indicating that BCAM0224 possesses two binding domains responsible for the interaction with collagen (Fig. 4a).

By using quantitative real-time PCR, we determined the expression profile of the BCAM0224 gene. We have observed that BCAM0224 gene expression elicited great changes for cells grown under environmental conditions that mimic the altered microenvironment of the CF lungs. Similar to our work, other studies on CF pathogens exposed to high osmolar conditions have shown a dramatic enhancement of the expression levels of other virulence genes, either from B. cenocepacia (Tomich \& Mohr, 2004; Bhatt \& Weingart, 2008) or Pseudomonas aeruginosa (Tan 
et al., 1999). Based on these observations, we speculate that expression of BCAM0224 may play a role in the virulence of B. cenocepacia when it infects CF patients.

With a non-polar BCAM0224 mutant and using adherence assays, we provide evidence supporting that BCAM0224 has a high affinity to binding collagen type I (Fig. 4b). This result is consistent with experiments in which recombinantly expressed BCAM0224 in an E. coli host was used (Fig. 4c). Using the G. mellonella larvae infection model, we demonstrated that the $\triangle B C A M 0224$ mutant strain displays a dramatic reduction in virulence compared with the wildtype strain (Fig. 4d). This behaviour may therefore be associated with the impaired ability of the $\triangle B C A M 0224$ mutant to attach properly to the host cells. These results are compatible with previous studies, which demonstrated that TAAs from other pathogenic bacteria interact with different ECM proteins, enabling them to promote an intimate association with target eukaryotic host cells (Zhang et al., 2004; Heise \& Dersch, 2006). Finally, upon sensing this contact, the bacteria translocate an arsenal of virulence factors directly from their cytoplasm into the host cells which cumulatively contribute to pathogenicity.

In conclusion, we identified a novel and unique putative adhesin cluster in the genome of $B$. cenocepacia located within a region that corresponds to an extension of the previously described $c c i$ island. Moreover, the defined PCR approach for one of the genes within this locus (BCAM0224) proved to be a suitable novel specific marker for discrimination of bacteria that belong to the ET-12 lineage of B. cenocepacia. Furthermore, we demonstrated that BCAM0224 from B. cenocepacia J2315 represents a new collagen-binding TAA with an important role in cellular adhesion and virulence.

\section{ACKNOWLEDGEMENTS}

This work was supported by FEDER and Fundação para a Ciência e a Tecnologia (FCT), Portugal (grants POCTI/BIO/58401/2004, PTDC/BIA-MIC/71453/2006 and PTDC/QUI/67925/2006). This work was carried out within the context of the PortugueseFrench Joint Research Program (Action F-20/06). A. M. F. acknowledges a sabbatical grant from FCT (BSAB-457). We thank J. Parkhill and M. Holden at the Wellcome Trust Sanger Institute for access to the annotation of the B. cenocepacia J2315 genome sequence prior to publication. We acknowledge Professor Gerd Döring from University of Tübingen in Germany, Professor John LiPuma from University of Michigan in the USA and Professor David Speert from University of British Columbia in Canada, who kindly provided Burkholderia strains. We also acknowledge Professor Miguel A. Valvano and Dr Daniel Aubert from University of Western, Ontario, Canada, who kindly provided plasmid pDA17.

\section{REFERENCES}

Achaz, G., Rocha, E. P., Netter, P. \& Coissac, E. (2002). Origin and fate of repeats in bacteria. Nucleic Acids Res 30, 2987-2994.
Achaz, G., Boyer, F., Rocha, E. P., Viari, A. \& Coissac, E. (2007). Repseek, a tool to retrieve approximate repeats from large DNA sequences. Bioinformatics 23, 119-121.

Anderson, D. S., Adhikari, P., Nowalk, A. J., Chen, C. Y. \& Mietzner, T. A. (2004). The hFbpABC transporter from Haemophilus influenzae functions as a binding-protein-dependent $\mathrm{ABC}$ transporter with high specificity and affinity for ferric iron. J Bacteriol 186, 62206229.

Baldwin, A., Sokol, P. A., Parkhill, J. \& Mahenthiralingam, E. (2004). The Burkholderia cepacia epidemic strain marker is part of a novel genomic island encoding both virulence and metabolismassociated genes in Burkholderia cenocepacia. Infect Immun 72, 1537-1547.

Benson, G. (1999). Tandem repeats finder: a program to analyze DNA sequences. Nucleic Acids Res 27, 573-580.

Bernier, S. P. \& Sokol, P. A. (2005). Use of suppression-subtractive hybridization to identify genes in the Burkholderia cepacia complex that are unique to Burkholderia cenocepacia. J Bacteriol 187, 52785291.

Bhatt, S. \& Weingart, C. L. (2008). Identification of sodium chlorideregulated genes in Burkholderia cenocepacia. Curr Microbiol 56, 418422.

Bichara, M., Wagner, J. \& Lambert, I. B. (2006). Mechanisms of tandem repeat instability in bacteria. Mutat Res 598, 144-163.

Cloud, K. A. \& Dillard, J. P. (2002). A lytic transglycosylase of Neisseria gonorrhoeae is involved in peptidoglycan-derived cytotoxin production. Infect Immun 70, 2752-2757.

Coenye, T., Spilker, T., Van Schoor, A., LiPuma, J. J. \& Vandamme, P. (2004). Recovery of Burkholderia cenocepacia strain PHDC from cystic fibrosis patients in Europe. Thorax 59, 952-954.

Cohan, F. M. (1994). Genetic exchange and evolutionary divergence in prokaryotes. Trends Ecol Evol 9, 175-180.

Comanducci, M., Bambini, S., Brunelli, B., Adu-Bobie, J., Aricò, B., Capecchi, B., Giuliani, M. M., Masignani, V., Santini, L. \& other authors (2002). NadA, a novel vaccine candidate of Neisseria meningitidis. J Exp Med 195, 1445-1454.

Dautin, N. \& Bernstein, H. D. (2007). Protein secretion in Gramnegative bacteria via the autotransporter pathway. Annu Rev Microbiol 61, 89-112.

Heise, T. \& Dersch, P. (2006). Identification of a domain in Yersinia virulence factor YadA that is crucial for extracellular matrix-specific cell adhesion and uptake. Proc Natl Acad Sci U S A 103, 33753380 .

Henderson, I. R., Navarro-Garcia, F., Desvaux, M., Fernandez, R. C. \& Ala'Aldeen, D. (2004). Type V protein secretion pathway: the autotransporter story. Microbiol Mol Biol Rev 68, 692-744.

Henikoff, S. \& Henikoff, J. G. (1992). Amino acid substitution matrices from protein blocks. Proc Natl Acad Sci U S A 89, 1091510919.

Hoiczyk, E., Roggenkamp, A., Reichenbecher, M., Lupas, A. \& Heesemann, J. (2000). Structure and sequence analysis of Yersinia YadA and Moraxella UspAs reveal a novel class of adhesins. EMBO J 19, 5989-5999.

Holden, M. T. G., Seth-Smith, H. M. B., Crossman, L. C., Mohammed, S., Stephen, D. B., Cerdeño-Tárraga, A. M., Thomson, N. R., Bason, N., Quail, M. A. \& other authors (2009). The genome of Burkholderia cenocepacia J2315, an epidemic pathogen of cystic fibrosis patients. J Bacteriol 191, 261-277.

Hughes, J. E., Stewart, J., Barclay, G. R. \& Govan, J. R. (1997). Priming of neutrophil respiratory burst activity by lipopolysaccharide from Burkholderia cepacia. Infect Immun 65, 4281-4287. 
Koretke, K. K., Szczesny, P., Gruber, M. \& Lupas, A. N. (2006). Model structure of the prototypical non-fimbrial adhesin YadA of Yersinia enterocolitica. J Struct Biol 155, 154-161.

Lafontaine, E. R., Cope, L. D., Aebi, C., Latimer, J. L., McCracken, G. H., Jr \& Hansen, E. J. (2000). The UspA1 protein and a second type of UspA2 protein mediate adherence of Moraxella catarrhalis to human epithelial cells in vitro. J Bacteriol 182, 1364-1373.

Linke, D., Riess, T., Autenrieth, I. B., Lupas, A. \& Kempf, V. A. (2006). Trimeric autotransporter adhesins: variable structure, common function. Trends Microbiol 14, 264-270.

Livak, K. J. \& Schmittgen, T. D. (2001). Analysis of relative gene expression data using real-time quantitative PCR and the $2^{-\Delta \Delta C T}$ method. Methods 25, 402-408.

Mahenthiralingam, E., Simpson, D. A. \& Speert, D. P. (1997). Identification and characterization of a novel DNA marker associated with epidemic Burkholderia cepacia strains recovered from patients with cystic fibrosis. J Clin Microbiol 35, 808-816.

Mahenthiralingam, E., Coenye, T., Chung, J. W., Speert, D. P., Govan, J. R., Taylor, P. \& Vandamme, P. (2000). Diagnostically and experimentally useful panel of strains from the Burkholderia cepacia complex. J Clin Microbiol 38, 910-913.

Mahenthiralingam, E., Urban, T. A. \& Goldberg, J. B. (2005). The multifarious, multireplicon Burkholderia cepacia complex. Nat Rev Microbiol 3, 144-156.

Moreira, L. M., Videira, P. A., Sousa, S. A., Leitão, J. H., Cunha, M. V. \& Sá-Correia, I. (2003). Identification and physical organization of the gene cluster involved in the biosynthesis of Burkholderia cepacia complex exopolysaccharide. Biochem Biophys Res Commun 312, 323333.

Riess, T., Andersson, S. G., Lupas, A., Schaller, M., Schäfer, A., Kyme, P., Martin, J., Wälzlein, J. H., Ehehalt, U. \& other authors (2004). Bartonella adhesin A mediates a proangiogenic host cell response. J Exp Med 200, 1267-1278.

Rocha, E. P. \& Blanchard, A. (2002). Genomic repeats, genome plasticity and the dynamics of Mycoplasma evolution. Nucleic Acids Res 30, 2031-2042.

Rocha, E. P., Danchin, A. \& Viari, A. (1999). Functional and evolutionary roles of long repeats in prokaryotes. Res Microbiol 150, 725-733.

Rutherford, K., Parkhill, J., Crook, J., Horsnell, T., Rice, P., Rajandream, M.-A. \& Barrell, B. (2000). Artemis: sequence visualisation and annotation. Bioinformatics 16, 944-945.

Sajjan, U. S., Xie, H., Lefebre, M. D., Valvano, M. A. \& Forstner, J. F. (2003). Identification and molecular analysis of cable pilus biosynthesis genes in Burkholderia cepacia. Microbiology 149, 961971.

Saunders, N. J., Jeffries, A. C., Peden, J. F., Hood, D. W., Tettelin, H., Rappuoli, R. \& Moxon, E. R. (2000). Repeat-associated phase variable genes in the complete genome sequence of Neisseria meningitidis strain MC58. Mol Microbiol 37, 207-215.

Segonds, C., Heulin, T., Marty, N. \& Chabanon, G. (1999). Differentiation of Burkholderia species by PCR-restriction fragment length polymorphism analysis of the 16S rRNA gene and application to cystic fibrosis isolates. J Clin Microbiol 37, 2201-2208.

Sokol, P. A., Sajjan, U., Visser, M. B., Gingues, S., Forstner, J. \& Kooi, C. (2003). The CepIR quorum-sensing system contributes to the virulence of Burkholderia cenocepacia respiratory infections. Microbiology 149, 3649-3658.
Szczesny, P. \& Lupas, A. (2008). Domain annotation of trimeric autotransporter adhesins - daTAA. Bioinformatics 24, 1251-1256.

Takahashi, Y., Yajima, A., Cisar, J. O. \& Konishi, K. (2004). Functional analysis of the Streptococcus gordonii DL1 sialic acid-binding adhesin and its essential role in bacterial binding to platelets. Infect Immun 72, 3876-3882.

Tamm, A., Tarkkanen, A. M., Korhonen, T. K., Kuusela, P., Toivanen, P. \& Skurnik, M. (1993). Hydrophobic domains affect the collagenbinding specificity and surface polymerization as well as the virulence potential of the YadA protein of Yersinia enterocolitica. Mol Microbiol 10, 995-1011.

Tan, M. W., Mahajan-Miklos, S. \& Ausubel, F. M. (1999). Killing of Caenorhabditis elegans by Pseudomonas aeruginosa used to model mammalian bacterial pathogenesis. Proc Natl Acad Sci U S A 96, 715720 .

Tomich, M. \& Mohr, C. D. (2004). Transcriptional and posttranscriptional control of cable pilus gene expression in Burkholderia cenocepacia. J Bacteriol 186, 1009-1020.

Tomich, M., Griffith, A., Herfst, C. A., Burns, J. L. \& Mohr, C. D. (2003). Attenuated virulence of a Burkholderia cepacia type III secretion mutant in a murine model of infection. Infect Immun 71, 14051415.

Turton, J. F., O’Brien, E., Megson, B., Kaufmann, M. E. \& Pitt, T. L. (2009). Strains of Burkholderia cenocepacia genomovar IIIA possessing the $c b l A$ gene that are distinct from ET12. Diagn Microbiol Infect Dis 64, 94-97.

Valle, J., Mabbett, A. N., Ulett, G. C., Toledo-Arana, A., Wecker, K., Totsika, M., Schembri, M. A., Ghigo, J. M. \& Beloin, C. (2008). UpaG, a new member of the trimeric autotransporter family of adhesins in uropathogenic Escherichia coli. J Bacteriol 190, 41474161.

Vandamme, P., Holmes, B., Coenye, T., Goris, J., Mahenthiralingam, E., LiPuma, J. J. \& Govan, J. R. (2003). Burkholderia cenocepacia sp. nov. - a new twist to an old story. Res Microbiol 154, 91-96.

Vanlaere, E., Baldwin, A., Gevers, D., Henry, D., De Brandt, E., LiPuma, J. J., Mahenthiralingam, E., Speert, D. P., Dowson, C. \& Vandamme, P. (2009). Taxon K, a complex within the Burkholderia cepacia complex comprises at least two novel species: Burkholderia contaminans sp. nov. and Burkholderia lata sp. nov. Int J Syst Evol Microbiol 59, 102-111.

Vinion-Dubiel, A. D. \& Goldberg, J. B. (2003). Lipopolysaccharide of Burkholderia cepacia complex. J Endotoxin Res 9, 201-213.

Visser, M. B., Majumdar, S., Hani, E. \& Sokol, P. A. (2004). Importance of the ornibactin and pyochelin siderophore transport systems in Burkholderia cenocepacia lung infections. Infect Immun 72, 2850-2857.

Wigfield, S. M., Rigg, G. P., Kavari, M., Webb, A. K., Matthews, R. C. \& Burnie, J. P. (2002). Identification of an immunodominant drug efflux pump in Burkholderia cepacia. J Antimicrob Chemother 49, 619624.

Zhang, P., Chomel, B. B., Schau, M. K., Goo, J. S., Droz, S., Kelminson, K. L., George, S. S., Lerche, N. W. \& Koehler, J. E. (2004). A family of variably expressed outer-membrane proteins (Vomp) mediates adhesion and autoaggregation in Bartonella quintana. Proc Natl Acad Sci U S A 101, 13630-13635.

Edited by: J. G. Shaw 